\title{
How is Middle School Students' Scientific Reasoning Ability Associated with Gender and Learning Environment?
}

\author{
Filiz Bezci ${ }^{1 *}$, Semra Sungur ${ }^{2}$ \\ ${ }^{1}$ Department of Educational Sciences, Çankırı Karatekin University, Çankırı, Turkey, ²Department of Mathematics and Science Education, Middle East \\ Technical University, Çankaya/Ankara, Turkey
}

*Corresponding Author: filizbezci@gmail.com

\section{ABSTRACT}

This study examined middle school students' scientific reasoning ability in relation to gender and learning environment perceptions. The data were obtained from 269 (148 girls and 121 boys) students. A two-tier multiple-choice test was used to assess students' scientific reasoning ability, while a Likert scale-type self-report questionnaire was used to assess students' learning environment perceptions. Results showed that there was no significant difference between girls and boys regarding their scientific reasoning abilities. On the other hand, students' scientific reasoning ability was found to be positively associated with involvement, task orientation, and teacher support, while it was negatively related to cooperation in science learning environments. Since students spent thousands of hours in classrooms, it is vital to examine and deepen the knowledge about the relationship between the learning environment and student outcomes. The current study presented and discussed considering the context of science education in Turkey; further studies can be conducted in different countries and contexts.

KEY WORDS: scientific reasoning ability; learning environment; gender; middle school students; science education

\section{INTRODUCTION}

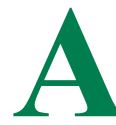

global and perennial goal of science education involves the preparation of scientifically literate individuals (AAAS, 1990, 1993; MONE, 2005, 2013, 2018; NRC, $1996,2012)$. Scientific literacy is defined in many ways and thus, there is no consensus about the definition of it. However, there are two mainstream visions about scientific literacy (Roberts, 2007). One is based on scientific concepts and processes, where scientifically literate individuals are expected to identify scientific concepts and engage in the scientific processes. The other one focuses on the interrelations among science, society, and humanities, as well as the differences between science and technology. According to the second one, scientifically literate individuals use scientific ideas, processes, and reasoning in science-related contexts and realize the relationship of science with society and science's contributions to the solution of social problems (Sadler and Zeidler, 2009). Therefore, to reach the goal of science education, students' scientific reasoning abilities emerge as an important component to be promoted (Gerber et al., 2001).

Kuhn (1993) examined the process of scientific reasoning as formal and informal reasoning. Formal reasoning includes the rules of logic and mathematics on fixed and unchanging premises (Perkins et al., 1991; Sadler, 2004). On the other hand, informal reasoning implies that students make inferences from indefinite premises based on ill-structured, open-ended, and debatable problems (Kuhn, 1993). In general, scientific reasoning is commonly accepted as a set of intellectual skills, which students need to have to do science and construct related concepts (Lawson et al., 2000; Voss et al., 1995). More specifically, based on the comprehensive literature review synthesis, Zimmerman (2000, 2005, 2007). Zimmerman mentioned scientific reasoning as the skills necessary to control variables, generate all combinations of solutions in multivariable tasks, choose or generate appropriate designs of experiments or tests, keep records, evaluate evidence, and reconstruct existing beliefs with the new evidence. Zimmerman went on to denote that scientific reasoning includes both conceptual understanding (domain-specific knowledge) and inquiry skills (domain general-strategies) which are interdependent to one another. Accordingly, conceptual understanding comprises content and structure of naive domain-specific mental theories, misconceptions, conceptual changes, and explanatory conformity. The researcher also added that investigating individuals' knowledge about phenomena in various content domains of science necessitates assessing their reasons for situations, answers to questions, or solutions to problems based on their current understanding. On the other hand, domain-general strategies include reasoning and problem-solving skills involved in the cycle of scientific inquiry. Moreover, a framework to examine the integration of the domain-general strategies with the domain-specific knowledge named as The Scientific Discovery as Dual Search (SDDS) was generated (Dunbar and Klahr, 1989; Klahr and Dunbar 1988). According to the framework, scientific 
reasoning is like a problem-solving activity containing a dualsearch process in two related problem spaces - the hypothesis space and the experiment space - to discover a hypothesis or theory. Later, Klahr $(2000,2005)$ updated the dual-search process focusing on the evidence evaluation process.

Although the theoretical background of scientific reasoning is extensive, the assessment of it is more limited. The "Group Assessment of Logical Thinking” (Roadrangka et al., 1982) and "The Test of Logical Thinking" (Tobin and Capie, 1981) are two of them. The "Classroom Test of Scientific Reasoning" (Lawson, 1978, 2000) is widely used in science education research to assess students' scientific reasoning ability (Han, 2013; Hanson, 2016). From an operational perspective, Lawson $(1978,2000)$ defined the scientific reasoning as a set of necessary skills for scientific inquiry and assessed it in terms of students' ability in grasping conservation of matter and volume (fundamental ideas of conservation and applications of conservation), proportional reasoning (basic information and application abilities about covariant relationships), control of variables (awareness of the associations between independent and dependent variables and application ability of those associations), probability reasoning (understanding combinational patterns to correctly interpret data and applying those combination patterns), correlation reasoning (ideas about relationships between two or more variables and application ability of those relationships), and hypothetical-deductive reasoning (major information and ability about scientific process as hypothesis testing). Lawson's (1978) “Classroom Test of Scientific Reasoning” was revised by Lawson (2000) as a two-tier multiple-choice test, which is more practical for classroom use and appropriate for the cognitive development level of $8^{\text {th }}$-grade students. Therefore, Lawson's Classroom Test of Scientific Reasoning (Lawson, 2000) was used to examine middle school students' scientific reasoning in the current study.

\section{Scientific Reasoning Ability and Gender}

Gender differences in science education outcomes have attracted the attention of science education researchers for many years (Dimitrov, 1999). Girls and women are commonly reported as exposed to inequalities in science education (Scantlebury and Baker, 2010). Many factors may trigger the gap between girls' and boys' science education outcomes. For instance, while children grow up if girls and boys are canalized to play different games with different toys; then they may develop different abilities which may affect their attitudes toward and engagement in courses later in their education life (Aldridge and Goldman, 2002; Tindall and Hamill, 2004). In general, boys tend to participate in more extracurricular activities related to physical sciences compared to girls (e.g., Dare and Roehrig, 2016). Similarly, in science classrooms, it is commonly reported that girls have passive roles such as following teachers' instructions, reading materials, making observations, and writing reports; however, boys actively engage in activities, such as leading discussions, dominating tinkering equipment, and using resources (Guzzetti and
Williams, 1996; Jones et al., 2000; Jovanovic and King, 1998; Woolfolk, 1998). Even teachers' expectations and behaviors can promote the stereotypical role of students in science classrooms and enlarge the difference in their performance (Guzzetti and Williams, 1996; Woolfolk, 1998).

Although gaining access to science education and the achievement of the girls increased in science in late 90s, their approaches toward science have been reported as unchanged (Altermatt et al., 1998). For example, according to the findings of a recent research study by Wieselmann et al. (2020), both genders were found to engage in the use of scientific equipment and materials equally in small group science activities, but girls were unlikely to take responsibility while handling the materials during the activities. Accordingly, the authors concluded that equity-related gender issues still existed. Examination of the related literature also indicated that there was a difference between boys and girls concerning scientific reasoning ability which was influential in their engagement in science classes. For example, girls were identified as better than boys in terms of correlational thinking (Demirtaş, 2011). On the other hand, boys were found to be better than girls concerning combinational thinking (Demirtaş, 2011), controlling variables, probabilistic thinking (Valanides, 1997), and proportional thinking (Yenilmez et al., 2005). In other studies, no significant gender differences were detected concerning scientific reasoning ability (Al-Zoubi et al., 2009; Hacıömeroğlu and Hacıömeroğlu, 2017; Piraksa et al., 2014; Talib et al., 2018; Valanides, 1996; Yüzüak, 2012). Since the above-mentioned studies were inconclusive regarding gender differences in scientific reasoning ability, there is a need for further examination of the association between these variables for a clearer understanding. As indicated in the aforementioned literature, the social environment has an influence on genderrelated issues. Thus, examination of the gender difference in different contexts could provide better insights. In line with this idea, the current study also aimed to investigate gender differences in $8^{\text {th }}$-grade Turkish middle school students' scientific reasoning ability.

\section{Scientific Reasoning Ability and Learning Environment Perception}

In the relevant literature, learning environment perceptions as an important factor contributing to the variance in student outcomes (Fraser and Walberg, 1991; Walberg, 1981, 1984) appear to be related to students' scientific reasoning ability (Gerber et al., 2001). The learning environment is a "social, psychological, and pedagogical context in which learning occurs and which affects students' achievement and attitudes" (Fraser, 1990, p. 3). The pioneering studies of Piaget (1965) and Vygotsky (1986) mentioned that direct experiences, cognitive conflict, social interaction, and discourse were important factors to the schemata in students' mind. Indeed, scientific reasoning can be considered as a measure of the complexities of children's cognitive frames (Adey and Shayer, 1990) and social-psychological nature of the classrooms has been regarded as an important factor effecting students' 
cognitive and affective learning outcomes (Fraser, 1998). For example, Haertel et al. (1981) indicated that students' perception about the social-psychological environment of their classes was related to their affective, behavioral, and cognitive-including formal reasoning outcomes. The direction of the relationship was positive which means that if students perceive the learning environment as positive, their learning outcomes are also positive or vice versa. Therefore, learning environments are likely to play important roles in students' scientific reasoning ability (Gerber et al., 2001). In the current study, students' learning environment perceptions were examined in terms of student cohesiveness, teacher support, involvement, investigation, task orientation, cooperation, and equity with using the What is Happening in This Class Questionnaire (Fraser et al., 1996) since the scale includes the contemporary cognitive approach to science education (Kim et al., 2000) and consistent with Turkish middle school science education curriculum in terms of social-psychological classroom atmosphere (Yerdelen, 2013).

Students' cohesiveness represents the interaction among students in terms of how friendly, helpful, and supportive they are to each other in the classroom (Yerdelen, 2013). Positive interdependence does more than simply motivate individuals to try harder; it facilitates the development of new insights and discoveries through promotive interaction (Gabbert et al., 1986; Johnson and Johnson 1981; Johnson et al., 1980; Skon et al., 1981). Moshman (1995) explained that much of reasoning ability is developed through social interaction. The interactions induce learners' cognitive processes and make it work in a more sophisticated way, especially for complex learning tasks (King, 2008). Therefore, a positive association is expected between cohesiveness in science classrooms and students' scientific reasoning ability.

Teacher support concerns the relationship between teacher and students concerning how helpful, friendly, and supportive teachers are to their students (Yerdelen, 2013). Teacher support has been conceptualized as teacher immediacy in many studies because teachers' immediacy is seen as the communicative behaviors which decrease the psychological distance (Mehrabian, 1966). Teachers' immediacy is seen as a significant predictor of teaching effectiveness (Anderson, 1979). For example, Kelly et al. (2015) indicated that instructors' positive communicative behaviors in an analytical reasoning course are mediated by students' psychological response to immediacy which is positively related with their motivation, while association is negative for math anxiety. Hence, it is predicted that there is a positive relationship between students' scientific reasoning ability and their science teachers' support.

Involvement dimension is about students' attentive interest to participate in class and sharing of their ideas in discussions (Yerdelen, 2013). Students' engagement in the activities and discourses helps them to understand and interpret scientific phenomena (NRC, 1996). Specifically, students' discourses in science classrooms represent their classroom practices and reflect their socially constructed reasoning and knowledge development (Cobb and Yackel, 1996). For example, Hogan et al. (2000) presented how the complexity of students' scientific reasoning is differentiated in teacher-guided and peer discussions. Accordingly, a positive association is expected between students' scientific reasoning ability and their involvement.

Investigation deals with students' skills and inquiry ability and their use in problem-solving and investigation (Yerdelen, 2013). In research, it has been reported that teaching science with inquiry-oriented teaching approaches promotes students scientific reasoning ability (e.g., Adey and Shayer 1990, Gerber et al., 2001; Lawson 1995, Marek and Cavallo 1997). Specifically, Gerber et al. (2001) studied $8^{\text {th }}$-grade students and the researchers indicated that students' scientific reasoning ability was higher in inquiry-based science classrooms with respect to non-inquiry-based ones. If students actively investigate during an activity, not depending on the content and the design of the activity, whether self-directed or structured, they enhance their scientific reasoning abilities (Kuhn et al., 1992). Even in the software-based learning environment, a positive association between middle school students' scientific reasoning ability and active investigation was reported (Kyza, 2009; Lee and She, 2010). Thus, a positive relationship between students' involvement and their scientific reasoning ability is expected.

Task orientation is about students' accomplishment of the given tasks and planned activities which students were expected to do (Yerdelen, 2013). Instruction assistance is important in scientific reasoning development (Lehrer et al., 2008). In different meta-analyses conducted on the effect of guidance on inquiry learning, the effectiveness of guidance on learning outcomes was revealed (Alfieri et al., 2011; Furtak et al., 2012). An effective guidance method implies restructuring inquiry tasks into controllable subtasks (Lazonder and Harmsen, 2016). For example, Lazonder and Kamp (2012) investigated the effect of splitting multivariable inquiry tasks into a series of single-variable subtasks on elementary school students focusing on the topic, use of the control variable strategies, and regulation of the learning process. The researchers detected that dividing a task into subtasks facilitates students' control variable strategies, a component of scientific reasoning, more than completing the whole task. Furthermore, structured task increases the performance of the learners (Rieber and Parmley, 1995). Therefore, a positive association is anticipated for task orientation and scientific reasoning ability.

Cooperation dimension indicates students' cooperation with each other during classroom activities (Yerdelen, 2013). According to Moshman (1995), because of egalitarian interaction among students, peer interaction has the optimal condition to develop reasoning skills. Johnson and Johnson (2008) indicated that group structure motivates the members to work together and enhances each other's learning in a successful cooperative learning manner, and this results in students achieving higher-level reasoning and problem-solving 
skills. The quality of reasoning is higher in cooperative learning than in competitive or individualistic learning (Johnson 2003; Johnson and Johnson, 1989, 2005). In addition, other research work provides support on the findings of the effectiveness of social interaction on students' reasoning skills, and these are expressed in different ways such as collaboration, peer interaction, cooperation, and many more (Dimant and Bearison, 1991; Kruger, 1992; Moshman, 1995; Samaha and De Lisi, 2000; Wegerif et al., 1999). Hence, a positive relationship between the cooperation of the students in science classroom and their scientific reasoning ability is predicted for the current study.

Equity emphasizes the teachers' equal treatment to each student in terms of feedback, praise, asking questions, and opportunities (Waldrip et al., 2009). If the teacher creates a conducive learning environment in which all students have the same and equal rights, it helps students' scientific reasoning development (Acar, 2015; Wilson et al., 2009). Therefore, a positive association between equity in the learning environment and students' scientific reasoning ability is expected for the present study.

\section{Rationale}

Thousands of hours allocated to students' education are spent in classrooms (Fraser, 2001). Students' experiences in specific learning environments are very important; hence, educational research has highlighted the relationship between learning environment and student outcome (Fraser, 2010). It is important that this association be examined in different countries considering the influence of social and cultural factors since cross-national educational research indicates that ordinary practices, beliefs, or attitudes for one country can be extraordinary or questionable for the other ones (Fraser, 1997). For instance, Aldridge et al. (1999) and Aldridge et al. (2000) indicated huge differences in the learning environments of Australia and Taiwan in the well-known cross-cultural study series. The reports indicated that the educational aims and the nature of the curricula in the two countries are different. In Taiwan, the educational system is more examination-based and highly competitive; parents, students and even teachers express that a good teacher possesses more content knowledge and uses teacher-centered methods. On the other hand, teachers in Australia believed that education should serve for the development of the students academically, socially, emotionally, and physically as a whole. Thus, they try to have good interpersonal relationships with their students and focus more on student-centered methods of teaching and learning. Moreover, classroom discipline and respect for teachers are more profound in Taiwan. Therefore, the association between the learning environment and students' outcomes is quite different with respect to the country in which the study is being conducted.

Indeed, relevant research demonstrated that the link between learning environment perceptions and adaptive student outcomes such as self-efficacy, metacognition, or achievement varies across studies conducted in different contexts (Ceylan and Berberoğlu, 2007; Gezer et al., 2018; Meral and Taş, 2017; Yerdelen, 2013). For example, Ceylan and Berberoglu (2007) found out that there was a negative relationship between student-centered learning activities such as carrying out experiments, doing projects, making discussions about assignments, and outcomes such as solving problems associated with daily lives as well as science achievement. This was based on TIMSS 1999 data obtained from a Turkish sample. On the other hand, the relationship between teacher-centered activities and student achievement was found to be positive. More specifically, the results indicated that the students were likely to be more successful in the science classrooms where teachers make explanations about the concepts and definitions, show how to solve problems, and ask students about what they know about the related topics. The researchers further noted that the reason behind these findings could be due to the familiarity of the students with teacher-centered approaches in Turkey. Indeed, in spite of the fact that Turkish middle school science curriculum is student-centered, the implemented curriculum differs from the written curriculum (Dindar and Yangin 2007). Students mostly experience teacher-centered classroom environments (Gökçe, 2006), and the educational system is exam-oriented and competitive (Sungur and Senler, 2009). Considering the varying effects of classroom learning environment on student-related outcomes depends on the context, it is reasonable to predict that the learning environments found to be conducive to students' reasoning ability in countries with non-competitive, student-centered educational systems may not be effective in countries where students are used to experiencing teacher-centered, competitive educational system. Thus, the purpose of the current study was to explore Turkish middle school students' scientific reasoning in relation to their classroom learning environment perceptions.

Gender differences in science education outcomes have attracted the attention of science education researchers for many years (Dimitrov, 1999). In earlier studies, it was commonly reported that boys outperformed girls (Steinkamp and Maehr, 1983), middle school years were the starting point of the differentiation (NCES, 2000) and girls tended to lose interest in science as they grew older (Greenfield, 1998). However, Kahle et al. (1993) asserted that the sociocultural factors which tended to guide the association between gender and science education were varying. Ericson and Ericson (1984) asserted that understanding the nature and pattern of performance differences between genders gives researchers the opportunity to explain the difference, if any and suggest ways to improve science education. In line with the recommendations of Ericson and Ericson (1984) and Kahle et al. (1993), the association between gender and students' scientific reasoning ability is examined in the current study.

\section{METHODS}

\section{Participants}

A total of 269 Grade 8 students (148 girls and 121 boys) participated in the study. Ethical considerations were taken 
into account when conducting the research. To get information about the background characteristic of the students, an elevenitem survey was administered to students. Items were about students' gender, age, last term science course grade, number of siblings, parents' educational level and their employment status, presence of a separate study room, a computer, and an internet connection. Students ranged in age from 14 to 16 years. Their mean science grade from the previous semester report card was $76.51(\mathrm{SD}=14.71)$. The participants were from low to middle socioeconomic status families. About three-quarters (75.5\%) of the participants' mothers were unemployed, while majority of their fathers $(87.4 \%)$ were employed. Majority of the participants' mothers (97.7\%) and fathers $(87.5 \%)$ had a high school degree and below. Only $6.3 \%$ of the participants were from single-child families. About $84 \%$ of participants had a study room and about $78 \%$ had a computer with an internet connection in their homes.

\section{Instruments}

\section{What is happening in this class questionnaire (WIHIC)}

Middle school students' learning environment perceptions in science classes were assessed using a 56 -item version of the WIHIC validated by Aldridge and Fraser (2000). It is a 5-point Likert scale ranging from 1 (never) to 5 (always). The WIHIC consists of seven sub-scales, namely: Student cohesiveness, teacher support, involvement, investigation, task orientation, cooperation, and equity. Sample items of the questionnaire were presented in the Appendix. In the current study, Cronbach's alpha coefficients ranged from 0.84 to 0.90 .

\section{Classroom test of scientific reasoning (CTSR)}

A revised version of the CTSR (Lawson, 2000) was used to assess students' scientific reasoning ability. The CTSR consisted of twelve two-tier multiple-choice items targeting six main aspects of the scientific reasoning namely: Conservation of mass and volume ( $\mathrm{n}=4$ items), proportional thinking $(\mathrm{n}=4$ items), control of variables $(\mathrm{n}=6$ items), probabilistic thinking ( $\mathrm{n}=4$ items), correlational thinking $(\mathrm{n}=2$ items), and hypothetical-deductive reasoning $(\mathrm{n}=4$ items). First-tier of each item required students to respond to a question and second-tier required students to select the best explanation for their answer. Items were scored one point only if students' responses to both tiers were correct. Maximum possible score that could be obtained on the test was thirteen. In the current study, reliability coefficient was found to be 0.55 for the whole test.

\section{RESULTS}

\section{Descriptive Statistics}

Students' scientific reasoning ability scores from the CTSR ranged from 0 to 10 with a mean of $2.29(\mathrm{SD}=1.84)$. This finding suggested that the participants' reasoning ability level was quite low and comparable for boys $(\mathrm{M}=2.13)$ and girls $(\mathrm{M}=2.42)$. Item level analysis also revealed that majority of the students could not respond to both tiers of all of 12 items in the test correctly. For example, only $8.6 \%$ of students could identify both the correct answer and selected the best explanation for one of the items assessing students' hypothetical-deductive reasoning. The item was about the burning candle: When a drinking glass is put over a burning candle standing in a pan of water, the candle quickly goes out, and the water rises into the glass. Based on this information, an explanation was provided as to why water rises into glass. Then, in the first tier of the item, students were asked if they are provided with these materials plus some matches and some dry ice how they could test this possible explanation. In the second tier of the items, students were also asked what result of their test stated in the first tier would indicate that the explanation was probably wrong (Lawson et al., 2000). A more striking example was from an item related to controlling variables: The item was about the response of fruit flies put into four sealed glass tubes to red light. In the first tier, students were asked, based on the experiment stated in the item, about the response of fruit flies. In the second tier, they were asked to select the best explanation for their choice (Lawson et al., 2000). Only $0.7 \%$ of the participants could respond to both tiers of the item correctly. Students were the most successful on one of the aspects' (conservation of mass and volume) items compared to their performance on other items. The item was about two balls of clay having the same shape, size, and weight. The students were asked what the relative weights of the pieces will be when one of the balls is flattened into a pancake shape (Lawson, 1978). About $46.1 \%$ of the participants could both recognize the correct answer and chose the best explanation for the item.

Concerning students' classroom learning environment perceptions, descriptive statistics, including mean and standard deviation, are summarized in Table 1. As shown in the table, the highest mean score was obtained on the equity sub-scale $(\mathrm{M}=3.69)$, implying that science teachers' equal treatment of each student in all science classroom activities. On the other hand, the lowest mean scores were obtained on investigation $(\mathrm{M}=3.26)$ subscale. Accordingly, although the mean scores were above mid-point of the 5-point Likert scale, it appeared that participants tended to work with other students in science classes and conducted experiments to answer questions or to test their ideas at moderate levels. A similar situation was observed for involvement $(\mathrm{M}=3.36)$ and teacher support ( $\mathrm{M}=3.39$ ) sub-scales. According to the results, perceived student cohesiveness $(\mathrm{M}=3.67)$ was a relatively higher level.

\begin{tabular}{lcc}
\hline $\begin{array}{l}\text { Table 1: Descriptive statistics for learning environment } \\
\text { perceptions }\end{array}$ & Mean & SD \\
\hline Variables & 3.67 & 0.80 \\
\hline Student cohesiveness & 3.39 & 0.97 \\
Teacher support & 3.36 & 0.98 \\
Involvement & 3.26 & 0.97 \\
Investigation & 3.65 & 0.69 \\
Task orientation & 3.27 & 0.95 \\
Cooperation & 3.69 & 0.99 \\
Equity & &
\end{tabular}


Thus, participants appeared to perceive that they worked well with other students in science classes.

\section{Inferential Statistics}

One-way ANOVA was conducted to determine whether gender made a difference in students' scientific reasoning ability. Results showed that there was no significant difference between boys $(\mathrm{M}=2.13, \mathrm{SD}=1.84)$ and girls $(\mathrm{M}=2.42, \mathrm{SD}=1.84)$ with respect to scientific reasoning ability, $\mathrm{F}(1,267)=1.62$, $\rho>0.05$.

Multiple regression analysis was conducted to explore the relationship between students' learning environment perceptions in science classes and their scientific reasoning ability. Results revealed that students' learning environment perceptions were significantly related to their scientific reasoning ability, $\mathrm{R}=.42, \mathrm{~F}(7,261)=8.13, \rho<0.05$. The model explained $17.9 \%$ of the variance in students' scientific reasoning ability. When the coefficients were examined, it was found that among learning environment perceptions variables, teacher support $\left(\beta=0.21, \mathrm{sr}^{2}=0.02\right)$, involvement $\left(\beta=0.32, \mathrm{sr}^{2}=0.04\right)$, task orientation $\left(\beta=0.18, \mathrm{sr}^{2}=0.02\right)$, and cooperation $\left(\beta=-0.22, \mathrm{sr}^{2}=0.02\right)$ were significantly associated with the dependent variable (Table 2 ). Thus, these findings imply that science learning environments where students have a good interpersonal relationship with their teacher (teacher support), are provided with opportunities to ask questions and to share and discuss their ideas (involvement), and remain on the task being aware of the goals of the activities and tasks (task orientation) tend to be conducive to students scientific reasoning ability. On the other hand, a negative relationship was found between cooperation and scientific reasoning ability. The relationship between remaining learning environment perception variables including student cohesiveness, investigation, and equity and scientific reasoning ability was not significant.

\section{DISCUSSION AND CONCLUSION}

Science education aims to raise scientifically literate individuals in society (AAAS, 1990, 1993; MONE, 2005, 2013, 2018; NRC, 1996, 2012). To realize that aim, all students should be accustomed to use scientific ideas, processes, and reasoning in their real-life situations (Sadler and Zeidler, 2009). Therefore, it is important to detect factors triggering a gap in science education outcomes to provide a remedy (Ericson and Ericson,

\begin{tabular}{lccc}
\hline $\begin{array}{l}\text { Table 2: Relationship between learning environment } \\
\text { perception and scientific reasoning ability }\end{array}$ & \\
\hline Predictor variables & $\boldsymbol{\beta}$ & $\boldsymbol{\rho}$ & $\mathbf{s r}^{\mathbf{2}}$ \\
\hline Student cohesiveness & -0.14 & 0.07 & 0.01 \\
Teacher support & 0.21 & 0.01 & 0.02 \\
Involvement & 0.32 & 0.00 & 0.04 \\
Investigation & 0.01 & 0.92 & 0.00 \\
Task orientation & 0.18 & 0.03 & 0.02 \\
Cooperation & -0.22 & 0.01 & 0.02 \\
Equity & -0.06 & 0.46 & 0.00 \\
\hline
\end{tabular}

1983). In this direction, the association between $8^{\text {th }}$-grade middle school students' gender and scientific reasoning ability was investigated in this study, and the results revealed that there was no significant difference between girls' and boys' scientific reasoning ability $(F(1,267)=1.62, \rho>0.05)$. This result was consistent with some other studies in the literature (Al-Zoubi et al., 2009; Hacıömeroğlu and Hacıömeroğlu, 2017; Piraksa et al., 2014; Valanides, 1996; Talib et al., 2018; Yüzüak, 2012). At this point, it is important to note that the association between students' gender and science-related outcome variables can be influenced by sociocultural factors (Kahle et al., 1993). For example, large-scale social responsibility projects and campaigns had been carried out against gender inequality in education until recently in Turkey. Such campaigns or projects may have played a role in the current finding that boys and girls are similar concerning their scientific reasoning abilities. However, as reported in the descriptive statistics, the mean scores were quite low for both genders; boys $(\mathrm{M}=2.13)$ and girls $(M=2.42)$. Thus, the findings suggest that necessary action should be taken to improve the scientific reasoning ability of both genders.

Results concerning the associations between students' reasoning ability and their learning environment perceptions reported in the subsequent paragraphs may provide clues for action to be taken in science classrooms. According to the findings, higher level of involvement (students' interest, satisfaction, and engagement in science activities), task orientation (students' accomplishment of the planned tasks and their awareness of the expectations), and teacher support were associated with higher levels of scientific reasoning ability. These findings are in line with the expectations. Because previously conducted studies pointed out that students' discourses in science classrooms (Cobb and Yackel, 1996; Hogan et al., 2000); engagement in splatted task into subparts (Lazonder and Kamp, 2012), structured tasks (Rieber and Parmley, 1995); having good interpersonal relationships with teachers (Kelly et al., 2015) contribute to their scientific reasoning ability development.

Therefore, enriching learning environments with these characteristics, informal educational settings can be used to advance students' scientific reasoning abilities. In fact, after synthesizing the results of the interventional studies, Zimmerman $(2000,2005,2007)$ presented that prompts, scaffolds, didactic instructions, and opportunities for particular types of practices maintain improvement on students' scientific reasoning ability. For example, using prompts in science classrooms provide improvements in the use of strategic requirements of the tasks (Kuhn and Phelps, 1982) and promotes self-explanations of concepts by the students (Chi et al., 1994). Accordingly, using prompts as teaching tools in science classrooms provides teacher support, involvement in classroom discussions and task orientation to students while advancing their scientific reasoning ability. Similarly, providing scaffolds may also create the same effect on both the learning environment and students' scientific reasoning. 
At this point, it is necessary to differentiate scaffoldings as provided by teacher and peers. Since the results of the currents study signified that mostly teacher-related variables such as teacher support and task orientation positively connected with students' scientific reasoning ability, but peer-related ones such as cohesiveness and cooperation have no or negative association with their scientific reasoning ability. Considering the contextual factors of the present study, as mentioned before, the common teacher-centered implementation tendency in science classrooms (Dindar and Yangın 2007; Gökçe, 2006) may trigger this distinction. However, this is a speculative explanation and needs further research to clarify this claim.

In addition, another way to enhance the scientific reasoning ability development of students in a learning environment is to use instruction assistance (Lehrer et al., 2008). As Zimmerman $(2000,2005,2007)$ mentioned, didactic instruction is a way to improve students' scientific reasoning, especially on control-of-variable strategies, and it ensures students' learning and strategic gains both in laboratory and classroom environments (Chen and Klahr, 1999; Klahr and Nigam, 2004; Toth et al., 2000). However, teachers should be careful about the limit of the information given for experimentation. Hence, rather than presenting experimentation as a prescribed and canonical method, it should be offered as a form of argument like modeling (Lehrer et al., 2001). Accordingly, if didactic instruction is implemented with paying attention to the critical points, the learning environment can provide teacher support, involvement, and task orientation which are positively associated with students' scientific reasoning ability. In addition, to provide students active participation, most activities in science curriculums are designed according to inquiry-oriented instruction. Inquiry-oriented instruction offers certain characteristics to the learning environment (Hofstein et al., 2001; Lin et al., 2009), and also, it is the most preferred way to promote students' scientific reasoning in research (e.g., Adey and Shayer 1990, Gerber et al., 2001; Lawson 1995, Marek and Cavallo 1997). Therefore, inquiry-oriented instruction can be used to arrange a learning environment to improve students' scientific reasoning ability. Moreover, Lawson (2004) signified that one-on-one sessions are helpful to develop students' scientific reasoning. Since it is not easy to apply informal education context, the researcher denoted that right implementation such as using hypothetico-deductive instruction also provide improvements in students' scientific reasoning. In such an instruction, students can be motivated to think on the explanations with its alternatives on the presented cases and they actively involve in classroom discussions to express their ideas.

On the other hand, association between other learning environment perception variables, including student cohesiveness, investigation, and equity and scientific reasoning ability, was non-significant. Unexpectedly the results presented that students' cooperation with each other in classroom activities negatively related with their scientific reasoning ability. The non-significant findings and the negative relationship found between cooperation and scientific reasoning ability can be partly explained by the context of the study: This study was conducted in Turkey. Although Turkish middle school science curriculum is student-centered, there is a discrepancy between written and implemented science curriculum in Turkey (Genç and Küçük, 2003). This is because science teachers tend to be more teacher-centered while implementing suggested activities to transmit knowledge to the students without providing opportunities for active participation (Gökçe, 2006; Kozandağı, 2001; Özmen, 2003). Thus, it may be reasonable that students who were not extensively exposed to student-centered activities, classroom environments encouraging cooperation, investigation, students' cohesiveness, or equity could not have contributed well to their scientific reasoning ability because scientific reasoning includes the skills necessary for scientific inquiry requiring open-ended activities in student-centered classrooms (Roth and Roychoudhury, 1993).

In addition, as a context of this current study, Turkish educational system is exam-oriented and highly competitive (Sungur and Şenler, 2009). In such a competitive system, normed referenced evaluation may encourage the students to study individually and cooperate less with their classmates to carry out classroom activities. However, it is important to note that quality of reasoning is better in cooperative learning than competitive or individualistic learning environments (Johnson 2003; Johnson and Johnson, 1989, 2005). Therefore, current findings suggest that there is a need to make revisions in science education programs and examination systems to create cooperative learning environments conducive to students' scientific reasoning abilities as an essential component of scientific literacy and having an important role in an individual's real-world life. In addition, the development of scientific reasoning in K-12 education is demonstrated to have a long-term effect on students' academic achievement (Adey and Shayer, 1994).

The results of the current study are presented and discussed considering the context of science education in Turkey. Hence, further studies can be conducted to examine the generalizability of the findings in other countries and in different contexts. In addition, the findings of the current cross-sectional study rely on the data obtained from self-reported instruments. Thus, there is a need for additional qualitative studies to clarify the associations between the variables of interest. In addition, longitudinal studies can be conducted to establish cause and effect relations.

\section{REFERENCES}

Acar, O. (2015). Examination of Science Learning Equity through Argumentation and Traditional Instruction Noting Differences in Socio-Economic Status. Science Education International, 26(1), 24-41.

Adey, P., \& Shayer, M. (1990) Accelerating the development of formal thinking in middle and high school students. Journal of Research in Science Teaching, 27, 267-285.

Adey, P., \& Shayer, M. (1994). Really Raising Standards. Routledge.

Aldridge, J.M., \& Fraser, B.J. (2000). A cross-cultural study of classroom 
learning environment in Australia and Taiwan. Learning Environment Research, 3, 101-134.

Aldridge, J.M., Fraser, B.J., \& Huang, T.C.I. (1999). Investigating classroom environments in Taiwan and Australia with multiple research methods. The Journal of Educational Research, 93(1), 48-62.

Aldridge, J.M., Fraser, B.J., Taylor, P.C., \& Chen, C.C. (2000). Constructivist learning environments in a cross-national study in Taiwan and Australia. International Journal of Science Education, 22, 37-55.

Aldridge, J., \& Goldman, R. (2002). Gender equity and education. In: Dragin, S., (Ed.), Current Issues and Trends in Education. pp. 163-170. Unwyn and Bacon.

Alfieri, L., Brooks, P.J., Aldrich, N.J., \& Tenenbaum, H.R. (2011). Does discovery-based instruction enhance learning? Journal of Educational Psychology, 103(1), 1-18.

Altermatt, E., Jovanovic, J., \& Perry, M. (1998). Bias or responsivity? Sex and achievement-level effects on teachers' classroom questioning practices. Journal of Educational Psychology, 90, 516-527.

Al-Zoubi, T., El-shar'a, I., \& Al-Salam, M.K. (2009). The scientific reasoning level of students' in the faculty of science in al-hussein bin talal university and its affection of gender, teaching level, and specialization. An-Najah University Journal for Research Humanities, 23(2), 401-437.

American Association for the Advancement of Science. (1990). Science for All Americans. Oxford University Press.

American Association for the Advancement of Science. (1993). Benchmarks for Science Literacy. Oxford University Press.

Anderson, J.F. (1979). Teacher Immediacy as a Predictor of Teaching Effectiveness: Communication Yearbook. Transaction Books.

Ceylan, E., \& Berberoglu, G. (2007). Factors Related with Students' Science Achievement: A Modeling Study. Education and Science, 32(144), 36-41.

Chen, Z., \& Klahr, D. (1999). All other things being equal: Acquisition and transfer of the control of variables strategy. Child Development, 70(5), 1098-1120.

Chi, M.T., De Leeuw, N., Chiu, M.H., \& LaVancher, C. (1994). Eliciting self-explanations improves understanding. Cognitive Science, 18(3), 439-477.

Cobb, P., \& Yackel, E. (1996). Constructivist, emergent, and sociocultural perspectives in the context of developmental research. Educational Psychologist, 31(3-4), 175-190.

Dare, E.A., \& Roehrig, G.H. (2016). "If I had to do it, then I would": Understanding early middle school students' perceptions of physics and physics-related careers by gender. Physical Review Physics Education Research, 12(2), 1-11.

Demirtaş, Z. (2011). Scientific reasoning skills of high school students' relationship gender and their academic success. International Journal of Human Sciences, 8(1), 1460-1471.

Dimant, R.J., \& Bearison, D.J. (1991). Development of formal reasoning during successive peer interactions. Dev Psychol, 27(2), 277.

Dimitrov, D.M. (1999). Gender differences in science achievement: Differential effect of ability, response format, and strands of learning outcomes. School Science and Mathematics, 99(8), 445-450.

Dindar, H., \& Yangin, S. (2007). Teachers' perceptions about the transition process to elementary school science and technology teaching curriculum. Kastamonu Education Journal, 15(1), 185-198.

Dunbar, K., \& Klahr, D. (1989). Developmental differences in scientifc discovery strategies. In D. Klahr \& K. Kotovsky (Eds.), Complex Information Processing: The Impact of Herbert A. Simon. pp. 109-143. Lawrence Erlbaum.

Erickson, G.A., \& Erickson, L.J. (1984) Achievement: Evidence, explanations, and implications. Science Education, 68, 63-89.

Fraser, B.J. (1990). Individualised Classroom Environment Questionnaire. Australian Council for Educational Research.

Fraser, B.J. (1997). NARST's Expansion, Internationalization and Crossnationalization 1996 Annual Meeting Presidential Address. NARST News, 40(1), 3-4.

Fraser, B.J. (1998). Classroom environment instruments development, validity and applications. Learning Environments Research, 1, 7-33.

Fraser, B.J. (2001). Twenty thousand hours. Learning Environments Research, 4, 1-5.

Fraser, B.J. (2010). Classroom Learning Enviroments. In S.K. Abel and N.
G. Lederman (Eds.), Handbook of Research on Science Education. pp. 103-124. Routledge.

Fraser, B.J., Fisher, D.L., \& McRobbie, C.J. (1996). Development, Validation and Use of Personal and Class Forms of a New Classroom Environment Instrument. New York: Paper Presented at the Annual Meeting of the American Educational Research Association.

Fraser, B.J., \& Walberg, H.J. (1991). Educational Environments: Evaluation Antecedents and Consequences. Pergamon Press.

Furtak, E.M., Seidel, T., Iverson, H., \& Briggs, D.C. (2012). Experimental and quasi-experimental studies of inquiry-based science teaching: A meta-analysis. Review of Educational Research, 82(3), 300-329.

Gabbert, B., Johnson, D.W., \& Johnson, R.T. (1986). Cooperative learning, group-to-individual transfer, process gain, and the acquisition of cognitive reasoning strategies. The Journal of Psychology, 120(3), 265278 .

Genç, H., \& Küçü, M. (2003). A Case Study about the Implementation of Student-Centered Program on Science Education. Paper Presented at the $12^{\text {th }}$ Educational Sciences Congress. pp. 1555-1572.

Gerber, B.L., Cavallo, A.M.L., \& Marek, E.A. (2001). Relationships among informal learning environments, teaching procedures and scientific reasoning ability. International Journal of Science Education, 23(5), 535-549.

Gezer, M., Meral, E., \& Şahin, İ.F. (2018) An analysis of the relations between classroom environment, achievement goal orientation and critical thinking through structural equation model. Kastamonu Education Journal, 26(3), 741-752.

Gökçe, İ. (2006). Evulation of the Inner Valume of the Science and Technology Curriculum and Teacher's Guide and the Problems Faced in the Practice (Ballkesir Example). Master's thesis, Balikesir University, Balikesir, Turkey.

Greenfield, T.A. (1998). Gender and grade-level differences in science interest and participation. Science Education, 81(3), 259-276

Guzzetti, B.J., \& Wilhams, W.O. (1996). Changing the pattern of gendered discussion: Lessons from science classrooms. Journal of Adolescent and Adult Literacy, 40, 38-47.

Hacıömeroğlu, G., \& Haciömeroğlu, E.S. (2017). Examining the relationship between gender, spatial ability, logical reasoning ability, and preferred mode of processing. Adiyaman University Journal of Educational Sciences, 7(1), 116-131.

Haertel, G.D., Walberg, H.J., \& Haertel, E.D. (1981). Socio-psychological environments and learning: a quantitative synthesis. British Educational Research Journal, 7(1), 27-36.

Han, J. (2013). The Assessment of Scientific Reasoning Skills of High School Science Students: A Standardized Assessment Instrument. Doctoral dissertation, Ohio State University, Columbus, Ohio, United States.

Hanson, S. (2016). The Assessment of Scientific Reasoning Skills of High School Science Students: A Standardized Assessment Instrument. Master's thesis, Illinois State University, United States.

Hofstein, A., Nahum, T.L., \& Shore, R. (2001). Assessment of the learning environment of inquiry-type laboratories in high school chemistry. Learning Environments Research, 4(2), 193-207.

Hogan, K., Nastasi, B.K., \& Pressley, M. (2000). Discourse patterns and collaborative scientific reasoning in peer and teacher-guided discussions. Cognition and Instruction, 17, 379-432.

Johnson, D.W. (2003). Social interdependence: The interrelationships among theory, research, and practice. American Psychologist, 58(11), 931-945.

Johnson, D.W., \& Johnson, R. (1989). Cooperation and Competition: Theory and Research. Interaction Book Company.

Johnson, D.W., \& Johnson, R. (2005). New developments in social interdependence theory. Genetic, Social, and General Psychology Monographs, 131(4), 285-358.

Johnson, D.W., \& Johnson, R.T. (1981). Effects of cooperative and individualistic learning experiences on interethnic interaction. Journal of Educational Psychology, 73(3), 444.

Johnson, D.W., Skon, L., \& Johnson, R. (1980). Effects of cooperative, competitive, and individualistic conditions on children's problemsolving performance. American Educational Research Journal, 17(1), 83-93.

Johnson, R.T., \& Johnson, D.W. (2008). Active learning: Cooperation in the classroom. The Annual Report of Educational Psychology in Japan, 47, 
29-30.

Jones, M.G., Brader-Araje, L., Carboni, L.W., Carter, G., Rua, M.J., Banilower, E., \& Hatch, H. (2000). Tool time: Gender and students' use of tools, control, and authority. Journal of Research in Science Teaching: The Official Journal of the National Association for Research in Science Teaching, 37(8), 760-783.

Jovanovic, J., \& King, S. (1998). Boys and girls in the performance-based science classroom: Who's doing the performing? American Educational Research Journal, 35, 477-496.

Kahle, J.B., Parker, L.H., Rennie, L.J., \& Riley, D. (1993). Gender differences in science education: Building a model. Educational Psychologist, 28, 379-404.

Kelly, S., Rice, C., Wyatt, B., Ducking, J., \& Denton, Z. (2015). Teacher immediacy and decreased student quantitative reasoning anxiety: The mediating effect of perception. Communication Education, 64(2), 171186.

Kim, H., Fisher, D.L., \& Fraser, B.J. (2000). Classroom environment and teacher interpersonal behaviour in secondary science classes in Korea. Evaluation and Research in Education, 14(1), 3-22.

King, A. (2008). Structuring peer interaction to promote higher-order thinking and complex learning in cooperating groups. In R. Gillies, A. Ashman, \& J. Terwel (Eds.), The Teacher's Role in Implementing Cooperative Learning in the Classroom. pp. 73-91. Springer.

Klahr, D. (2000). Exploring Science: The Cognition and Development of Discovery Processes. MIT Press.

Klahr, D. (2005). A framework for cognitive studies of science and technology. In M. Gorman, R. D. Tweney, D. C. Gooding, \& A. P. Kincannon (Eds.), Scientific and Technological Thinking. pp. 81-95. Lawrence Erlbaum.

Klahr, D., \& Dunbar, K. (1988). Dual search space during scientific reasoning. Cognitive Science, 12, 1-48.

Klahr, D., \& Nigam, M. (2004). The equivalence of learning paths in early science instruction: Effects of direct instruction and discovery learning. Psychological Science, 15(10), 661-667.

Kozandağı, İ. (2001). The Problems Faced in the Curriculum of Science Lesson in the Fourth and Fifth Classes of the Elementary Schools and the Solution Suggestions According to the Opinions of the Teachers. Master's thesis, Dokuz Eylül University, İzmir, Turkey.

Kruger, A.C. (1992). The effect of peer and adult-child transactive discussions on moral reasoning. Merrill-Palmer Quarterly, 1982, 191-211.

Kuhn, D. (1993). Connecting scientific and informal reasoning. MerrillPalmer Quarterly, 39, 74-103.

Kuhn, D., \& Phelps, E. (1982). The development of problem-solving strategies. In H. Reese (Ed.), Advances in Child Development and Behavior. pp. 1-44. Vol. 17. Academic Press.

Kuhn, D., Schauble, L., \& Garcia-Mila, M. (1992). Cross-domain development of scientific reasoning. Cognition and Instruction, 9(4), 285-327.

Kyza, E.A. (2009). Middle-school students' reasoning about alternative hypotheses in a scaffolded, software-based inquiry investigation. Cognition and Instruction, 27(4), 277-311.

Lawson, A.E. (1978). The development and validation of classroom test of formal reasoning. Journal of Research in Science Teaching, 15(1), 1124.

Lawson, A.E. (1995). Science Teaching and the Development of Thinking. Wadsworth Publishing.

Lawson, A.E. (2000). Classroom Test of Scientific Reasoning. Arizona State University.

Lawson, A.E. (2004). The nature and development of scientific reasoning: A synthetic view. International Journal of Science and Mathematics Education, 2(3), 307.

Lawson, E.A., Clark, B., Cramer-Meldrum, E., Falconer, A.K., Sequist, M.J., \& Kwon, Y. (2000). Development of scientific reasoning in college biology: Do two levels of general hypothesis-testing skills exist? Journal of Research in Science Teaching, 37(1), 81-101.

Lazonder, A.W., \& Harmsen, R. (2016). Meta-analysis of inquiry-based learning: Effects of guidance. Review of Educational Research, 86(3), 681-718

Lazonder, A.W., \& Kamp, E. (2012). Bit by bit or all at once? Splitting up the inquiry task to promote children's scientific reasoning. Learning and
Instruction, 22(6), 458-464.

Lee, C.Q., \& She, H.C. (2010). Facilitating students' conceptual change and scientific reasoning involving the unit of combustion. Research in Science Education, 40(4), 479-504.

Lehrer, R., Schauble, L., \& Lucas, D. (2008). Supporting development of the epistemology of inquiry. Cognitive Development, 23(4), 512-529.

Lehrer, R., Schauble, L., \& Petrosino, A.J. (2001). Reconsidering the role of experiment in science education. In K. Crowley, C. Schunn, \& T. Okada (Eds.), Designing for Science: Implications from Everyday, Classroom, and Professional Settings. pp. 251-278. Erlbaum.

Lin, H.S., Hong, Z.R., \& Cheng, Y.Y. (2009). The interplay of the classroom learning environment and inquiry-based activities. International Journal of Science Education, 31(8), 1013-1024.

Marek, E.A., \& Cavallo, A.M.L. (1997). The Learning Cycle and Elementary School Science. Heinemann.

Mehrabian, A. (1966). Immediacy: An indicator of attitudes in linguistic communication. Journal of Personality, 34, 26-34.

Meral, E., \& Taş, Y. (2017). Modelling the relationships among social studies learning environment, self-efficacy, and critical thinking disposition. Pegem Journal of Education and Instruction, 7(3), 349-366.

Ministry of National Education of Turkey (MONE). (2005). Science and Technology Curriculum of Elementary Schools. Board of Education.

Ministry of National Education of Turkey (MONE). (2013). Science Curriculum of Elementary Schools. Turkey: Board of Education.

Ministry of National Education of Turkey (MONE). (2018). Science Curriculum of Elementary Schools. Turkey: Board of Education.

Moshman, D. (1995). Reasoning as self-constrained thinking. Human Development, 38(1), 53-64.

National Center for Education Statistics. (2000). The NAEP Science Scale. Available from: http://www.nces.ed.gov/nationsreportcard/science/ scale.asp. [Last accesed on 2020 Jan 16].

National Research Council. (1996). National Science Education Standards. National Academy Press.

National Research Council. (2012). A Framework for K-12 Science Education: Practices, Crosscutting Concepts, and Core Ideas. The National Academies Press.

Özmen, Ş.G. (2003). Surveying of Science Teachers Opinions on Constructivist Learning Approach. Master's thesis. Hacettepe University, Ankara, Turkey.

Perkins, D.N., Farady, M., \& Bushey, B. (1991). Everyday reasoning and the roots of intelligence. In: Voss, J.F., Perkins, D.N., \& Segal, J.W., (Eds.), Informal Reasoning and Education. pp. 83-105. Lawrence Erlbaum Associates, Inc.

Piaget, J. (1965). The stages of the intellectual development of the child Educational Psychology in Context: Readings for Future Teachers. pp. 98-106. Sage.

Piraksa, C., Srisawasdi, N., \& Koul, R. (2014). Effect of gender on student's scientific reasoning ability: A case study in Thailand. Procedia-Social and Behavioral Sciences, 116, 486-491.

Rieber, L.P., \& Parmley, M.W. (1995). To teach or not to teach? Comparing the use of computer-based simulations in deductive versus inductive approaches to learning with adults in science. Journal of Educational Computing Research, 13(4), 359-374.

Roadrangka V., Yeany, R.H., \& Padilla M.J. (1982). GALT. Group Test of Logical Thinking. University of Georgia.

Roberts, D.A. (2007). Scientific literacy/science literacy. In N.G. Lederman \& S.K. Abell (Eds.), Handbook of Research on Science Education. pp. 729-780. Routledge.

Roth, W.M., \& Roychoudhury, A. (1993). The development of science process skills in authentic contexts. Journal of Research in Science Teaching, 30(2), 127-152.

Sadler, T.D. (2004). Informal reasoning regarding socioscientific issues: A critical review of research. Journal of Research in Science Teaching, 41, 513-536.

Sadler, T.D., \& Zeidler, D.L. (2009). Scientific literacy, PISA, and socioscientific discourse: Assessment for progressive aims of science education. Journal of Research in Science Teaching: The Official Journal of the National Association for Research in Science Teaching, 46(8), 909-921.

Samaha, N.V., \& De Lisi, R. (2000). Peer collaboration on a nonverbal 
reasoning task by urban, minority students. The Journal of Experimental Education, 69(1), 5-21.

Scantlebury, K., \& Baker, D. (2010). Gender issues in science education research: Remembering where the difference lies. In N.G. Lederman \& S.K. Abell (Eds.), Handbook of Research on Science Education. pp. 257-286. Routledge.

Skon, L., Johnson, D.W., \& Johnson, R.T. (1981). Cooperative peer interaction versus individual competition and individualistic efforts: Effects on the acquisition of cognitive reasoning strategies. Journal of Educational Psychology, 73(1), 83.

Steinkamp, M.W., \& Maehr, M.L. (1983). Affect, ability, and science achievement: A quantitative synthesis of correlational research. Review of Educational Research, 53, 369-396.

Sungur, S., \& Senler, B. (2009). An analysis of Turkish high school students' metacognition and motivation. Educational Research and Evaluation, $15(1), 45-62$.

Talib, C.A., Rajan, S.T., Hakim, N.W.A., Malik, A.M.A., Siang, K.H., \& Ali, M. (2018). Gender Difference as a Factor in Fostering Scientific Reasoning Skill Among Students. In: 2018 IEEE 10 $0^{\text {th }}$ International Conference on Engineering Education, IEEE. pp. 54-58.

Tindall, T., \& Hamil, B. (2004). Gender disparity in science education: The causes consequences and solutions. Gender Disparity in Science Education, 125, 282-296.

Tobin, K.G., \& Capie, W. (1981). Development and validation of a group test of logical thinking. Educational and Psychological Measurement, 41(2), 413-414

Toth, E.E., Klahr, D., \& Chen, Z. (2000). Bridging research and practice: A cognitively based classroom intervention for teaching experimentation skills to elementary school children. Cognition and Instruction, 18(4), 423-459.

Valanides, N. (1997). Formal Reasoning Abilities and School Achievement. Studies in Educational Evaluation, 23(2), 169-85.

Valanides, N.C. (1996). Formal reasoning and science teaching. School Science and Mathematics, 96(2), 99-107.

Voss, J.F., Wiley, J., \& Carretero, M. (1995). Acquiring intellectual skills. Annual Review of Psychology, 46(1), 155-181.

Vygotsky, L. (1986) Thought and Language. The MIT Press.

Walberg, H.J. (1981). A psychological theory of educational productivity. In
F. Farley \& N. Gordon (Eds.), Psychology and Education. pp. 81-110B. McCutchan.

Walberg, H.J. (1984). Improving the productivity of America's schools. Educational Leadership, 41(8), 19-27.

Waldrip, B.G., Fisher, D.L., \& Dorman, J. (2009). Identifying examplary science teachers through students' perceptions of their learning environment. Learning Environment Research, 12, 1-13.

Wegerif, R., Mercer, N., \& Dawes, L. (1999). From social interaction to individual reasoning: An empirical investigation of a possible sociocultural model of cognitive development. Learning and Instruction, 9(6), 493-516.

Wieselmann, J.R., Dare, E.A., Ring-Whalen, E.A., \& Roehrig, G.H. (2020). "I just do what the boys tell me": Exploring small group student interactions in an integrated STEM unit. Journal of Research in Science Teaching, 57(1), 112-144.

Wilson, C.D., Taylor, J.A., Kowalski, S.M., \& Carlson, J. (2009). The Relative Effects of Inquiry-Based and Commonplace Science Teaching on Students' Knowledge, Reasoning and Argumentation about Sleep Concepts: A Randomized Control Trial. Paper Presented at The Society for Research on Educational Effectiveness, Evanston, IL.

Woolfolk, A.E. (1998). Educational Psychology. $3^{\text {rd }}$ ed. Allyn and Bacon.

Yenilmez, A., Sungur, S., \& Tekkaya, C. (2005). Investigating students' logical thinking abilities: The effects of gender and grade level Hacettepe University Journal of Education, 28(28), 219-225.

Yerdelen, S. (2013). Multilevel Investigations of Students' Cognitive and Affective Learning Outcomes and their Relationships with Perceived Classroom Learning Environment and Teacher Effectiveness. Doctoral dissertation, Middle East Technical University, Ankara, Turkey.

Yüzüak, A.V. (2012). Adaptation and Application of Lawson's Classroom Test of Science Reasoning. Master's thesis, Gazi University, Ankara, Turkey.

Zimmerman, C. (2000). The development of scientific reasoning skills. Developmental Review, 20, 99-149.

Zimmerman, C. (2005). The Development of Scientific Reasoning Skills: What Psychologist Contribute to an Understanding of Elementary Science Learning. Illinois State University.

Zimmerman, C. (2007). The development of scientific thinking skills in elementary and middle school. Developmental Review, 27, 172-223. 


\section{APPENDIX}

\section{Sample items of what is happening in this class questionnaire (WIHIC)}

\begin{tabular}{|c|c|}
\hline Sub-scale of WIHIC & Sample Item \\
\hline cohesiveness & $\begin{array}{l}\text { I help the other class members who are } \\
\text { having trouble with their work. }\end{array}$ \\
\hline teacher support & $\begin{array}{l}\text { The teacher helps me when I have trouble } \\
\text { with the work. }\end{array}$ \\
\hline involvement & $\begin{array}{l}\text { My ideas and suggestions are used during } \\
\text { classroom discussions. }\end{array}$ \\
\hline investigation & I carry out investigations to test my ideas. \\
\hline task orientation & $\begin{array}{l}\text { Getting a certain amount of work done is } \\
\text { important to me. }\end{array}$ \\
\hline cooperation & $\begin{array}{l}\text { I cooperate with other students on } \\
\text { class activities. }\end{array}$ \\
\hline equity & $\begin{array}{l}\text { My work receives as much as praise as } \\
\text { other students' work. }\end{array}$ \\
\hline
\end{tabular}

